\title{
ACCURATE SINGLE-SECTION MODEL OF MOSFET INCLUDING SUBSTRATE RESISTIVITY
}

\author{
UMESH KUMAR \\ Fellow, IETE; Senior Member, IEEE, Department of Electrical Engineering, \\ Indian Institute of Technology, Delhi, Hauz Khas, New Delhi-110016, India \\ (Received April 17, 1990; in final form August 23, 1990)
}

\section{INTRODUCTION}

Practical MOSFETS fabricated on low and moderately doped substrates depart considerably from the idealized two-port model because of the control properties of the substrate terminal. Therefore, the need arises to characterise these double control devices as a 4 terminal, 3-port active network. The purpose of this work is to present a new model in the general case of the MOSFET structure including substrate control effects by suitable approximation of the MOSFET terminal admittances. Device admittances are calculated in terms of the 'Uniform RC double transmission line'.

The combined gate-substrate excitation mode can be treated in terms of an RC transmission line having a single, non-uniform capacitance distribution and a uniform resistance similar to the case of negligible substrate effects. The separate gate and substrate excitation modes, however, require for their representation an RC transmission line analog having two nonuniform capacitance distributions. We have the admittance parameters as:

$$
\begin{aligned}
& \mathrm{Y}_{21}=\mathrm{g}_{\mathrm{o}}\{(1-\mathrm{k}) \theta \operatorname{Cosech} \theta+(\gamma-1+\mathrm{k}) \theta \operatorname{Coth} \theta \\
& \mathrm{Y}_{11}=\frac{\mathrm{j} \omega \mathrm{C}_{\mathrm{u}}}{\theta^{2}}\{\theta \operatorname{Coth} \theta-\theta \operatorname{Cosech} \theta\}(2-2 \mathrm{k}-\gamma)+\mathrm{j} \omega \mathrm{C}_{\mathrm{u}} \mathrm{k} \\
& \mathrm{Y}_{31}=\mathrm{j} \omega \mathrm{C}_{\mathrm{u}}^{\prime} \frac{\gamma}{2}-\frac{\mathrm{C}_{\mathrm{u}}^{\prime}}{\mathrm{C}_{\mathrm{u}}} \mathrm{y}_{11}
\end{aligned}
$$

Where $\theta^{2}=\mathrm{j} \omega\left(\mathrm{C}_{\mathrm{u}}+\mathrm{C}_{\mathrm{u}}^{\prime}\right) \varphi_{\mathrm{o}} ; \mathrm{k}=\frac{\mathrm{C}_{\mathrm{u}}^{\prime}}{\mathrm{C}_{\mathrm{u}}+\mathrm{C}_{\mathrm{u}}^{\prime}} ;$ and $\gamma \cong \frac{\mathrm{V}_{\text {sat }}}{\mathrm{V}_{\mathrm{g}}}$

The accurate continued fraction expansions are:

$$
\left.\left.\theta \operatorname{Coth} \theta=\theta\left(\frac{1}{\theta}+1 /\left(\frac{3}{\theta}+1 / \frac{5}{\theta}+1 /\left(\frac{7}{\theta}\right)\right)\right)\right)\right)
$$

$\& \theta \operatorname{Cosech} \theta=\theta\left(\frac{1}{\theta}+1 /\left(-\frac{6}{\theta}+1 /\left(-\frac{10}{7 \theta}+1 /\left(\frac{686}{11 \theta}\right)\right)\right)\right)$ 
Based on these expansions, a 4-terminal model similar to the 'DAS' model $^{1}$ can be constructed that gives an equivalent circuit of the MOSFET including substrate resistivity effects.

\section{F.A. LINDHOLM \& P.R. GRAYS' MODELS ${ }^{2}$ FOR ARBITRARILY- DOPED FOUR-TERMINAL FIELD-EFFECT TRANSISTORS}

Models are derived for a four-terminal field-effect transistor (FTFET) with an arbitrary (one-dimensional) impurity distribution. The models apply for both fourterminal and conventional three-terminal devices operated either in the pinch off or non-pinch off modes. Moreover, they describe behavior when either large or small signals are applied to the gates. The model parameters can be determined either from terminal measurements or from knowledge of the physical composition. Because an arbitrary impurity distribution is assumed in their derivation, the models represent devices made with any of the common fabrication techniques. Measured step-function response of the epitaxial, single-diffused, and double-diffused FTFET's shows good agreement with calculated behavior for broad ranges of resistive source and load termination.

\section{A.1 Derivatives of Drain Current}

Nonpinch-off Mode: By differentiating the general expression for drain current given by Cobbold and Trofimenk-off ${ }^{3}$ the operation in the non-pinch off region is given as follows:

$(\mathrm{L} / \mathrm{Z}) \mathrm{g}_{\mathrm{m} 1}=\mathrm{F}\left[\mathrm{a}-\mathrm{Y}_{1}\left(\mathrm{VG}_{1}-\mathrm{V}_{\mathrm{D}}\right), \mathrm{a}-\mathrm{Y}_{1}\left(\mathrm{VG}_{1}\right)\right]$

$(\mathrm{L} / \mathrm{Z}) \mathrm{g}_{\mathrm{m} 2}=\mathrm{F}\left[-\mathrm{a}+\mathrm{Y}_{2}\left(\mathrm{VG}_{2}\right),-\mathrm{a}+\mathrm{Y}_{2}\left(\mathrm{VG}_{2}-\mathrm{V}_{\mathrm{D}}\right)\right]$

$(\mathrm{L} / \mathrm{Z}) \mathrm{g}_{22}=\mathrm{F}\left[-\mathrm{a}+\mathrm{Y}_{2}\left(\mathrm{VG}_{2}-\mathrm{V}_{\mathrm{D}}\right), \mathrm{a}-\mathrm{Y}_{1}\left(\mathrm{VG}_{1}-\mathrm{V}_{\mathrm{D}}\right)\right]$

where $\mathrm{F}(\gamma, \mathrm{s})=\int_{\gamma,}^{\mathrm{s}} \mu(\mathrm{y}) \varphi(\mathrm{y}) \mathrm{dy}$

Combining the neutrality condition,

$\int_{Y_{1} g\left(W_{2}\right)}^{Y_{1} g\left(W_{1}\right)} \varphi(y) d y=0$

With the relation for the voltage across the depletion layer

$\mathrm{W}_{1}\left(\mathrm{Y}_{1}\right)=(\mathrm{Y} \varepsilon) \int_{-\mathrm{Y}_{\mathrm{lg}}}^{\mathrm{Y}_{1}} \mathrm{y}^{\prime} \varphi\left(\mathrm{y}^{\prime}\right) \mathrm{dy^{ \prime }}, \mathrm{y}^{\prime}=\mathrm{a}-\mathrm{y}$

For a specified voltage $W_{1}\left(\right.$ e.g. $\left.W_{1}=V_{1}-V_{D}\right)$, the corresponding value of $\mathrm{Y}_{1}$ can be solved. 
Pinch off mode: In this mode, eqn. (1) to (3) still hold if $\mathrm{V}_{\mathrm{D}}$ is replaced by $\mathrm{V}_{\mathrm{DP}}$, in accordance with the argument leading to eqn.

$\mathrm{Y}_{1}\left(\mathrm{VG}_{1}-\mathrm{V}_{\mathrm{DP}}\right)+\mathrm{Y}_{2}\left(\mathrm{VG}_{2}-\mathrm{V}_{\mathrm{DP}}\right)=2 \mathrm{a}$

Therefore, the $\mathrm{g}_{22}$ (of the intrinsic device) vanishes in the pinch off mode.

A.2 Depletion Charge and its Derivatives:

Expression for $\mathrm{Q}_{1}$ for arbitrarily doped devices

$$
\begin{aligned}
\frac{\partial \mathrm{W}_{1}}{\partial} & =\frac{\partial \mathrm{W}_{2}}{\partial \mathrm{x}}=\mathrm{I}_{\mathrm{D}} / \mathrm{ZF}\left[-\mathrm{a}+\mathrm{Y}_{2}\left(\mathrm{~W}_{2}\right), \mathrm{a}-\mathrm{Y}_{1}\left(\mathrm{~W}_{1}\right)\right] \\
\mathrm{Q}_{1} & =\mathrm{Z} \int_{\mathrm{O}}^{\mathrm{L}}\left[\underset{\mathrm{a}-\mathrm{Y}_{1}}{\operatorname{a}}(\mathrm{y}) \mathrm{dy}\right] \mathrm{dx} \text { (as shown in Fig. 1(a)) }
\end{aligned}
$$

Thus, by eqns. (8) \& (9)

$$
\begin{aligned}
Q_{1}=\left(Z^{2} / I_{D}\right) & \int_{W_{1} S}^{W_{1} D}\left(q_{1}\left(W_{1}\right)\right) \\
& \times F\left[-a+Y_{2}\left(W_{1}-V_{1}+V_{2}\right), a-Y_{1}\left(W_{1}\right)\right] d W_{1} \\
& \text { where } q_{1}\left(W_{1}\right)=\int_{a-Y_{1}\left(W_{1}\right)}^{a} \varphi(y) d y
\end{aligned}
$$

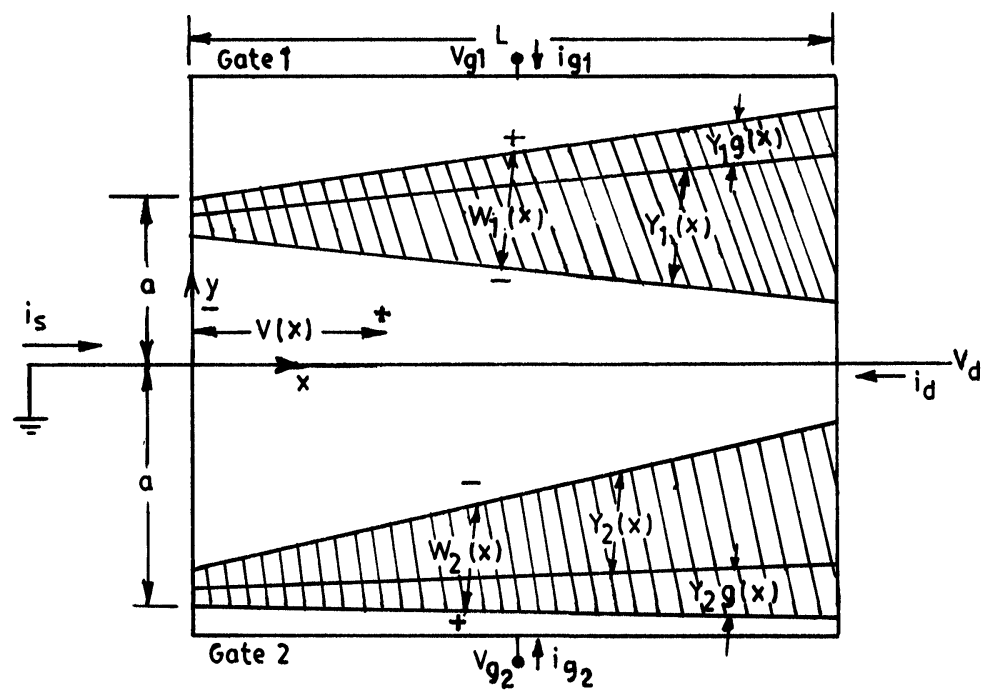

Fig:1(a)

FIGURE 1a A Four-terminal field effect transistor with rectangular geometry. 


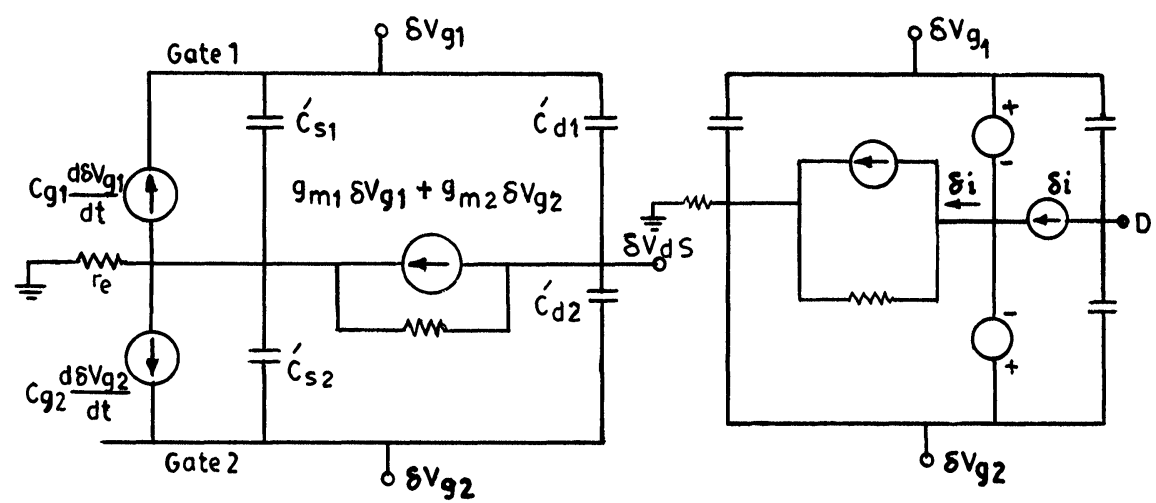

Fig:1(b)

Fig:1(c)

FIGURE 1b Small-signal model for operation beyond pinch-off with several extrinsic elements added. The printed capacitances includes extrinsic components. The fig. shows one method for accounting for $r_{c}$, the extrinsic source resistance.

FIGURE 1c Form of model proposed by Hudson for a symmetrical abrupt junction FTFET operated beyond pinch-off and excited by small signals. The sources shown are dependent source.

is the charge per unit area depleted from the channel below gate 1 and in which $\mathrm{W}_{1} \mathrm{~S}$ and $\mathrm{W}_{1} \mathrm{D}$ represent the voltages across the depletion region at the source and drain, respectively. For non-pinch off operation;

$\mathrm{W}_{1} \mathrm{~S}=\mathrm{VG}_{1}$

$\mathrm{W}_{1} \mathrm{D}=\mathrm{VG}_{1}-\mathrm{V}_{\mathrm{D}}$

For pinch off operation, eqn. (11) will be the same but $\mathrm{W}_{1} \mathrm{D}$ will be determined by

$\mathrm{Y}_{1}\left(\mathrm{~W}_{1} \mathrm{D}\right)+\mathrm{Y}_{2}\left(\mathrm{VG}_{2}-\mathrm{VG}_{1}+\mathrm{W}_{1 \mathrm{D}}\right)=2 \mathrm{a}$

The model shown in Fig. 1(c), proposed by Hudson ${ }^{4}$ pertains to a symmetrical abrupt junction device that is operated in the pinch off region and excited by small signals. In the Hudson model, each element bears a close relationship with a physical process occuring within the device. The model of Fig. 1(b) ties less obviously with the physics but it is easier to use in network calculations.

\section{BASIC EQUATIONS FOR DAS MODEL}

The majority carrier current $\mathrm{I}$, which flows in the channel region of a MOS transistor under appropriate bias condition, as shown in Fig. 2, is determined by the given equation

$\mathrm{I}=2 \bar{\mu}_{\mathrm{s}} \mathrm{Q}_{\mathrm{n}} \frac{\partial \mathrm{V}_{\mathrm{x}}}{\partial \mathrm{x}}$ 


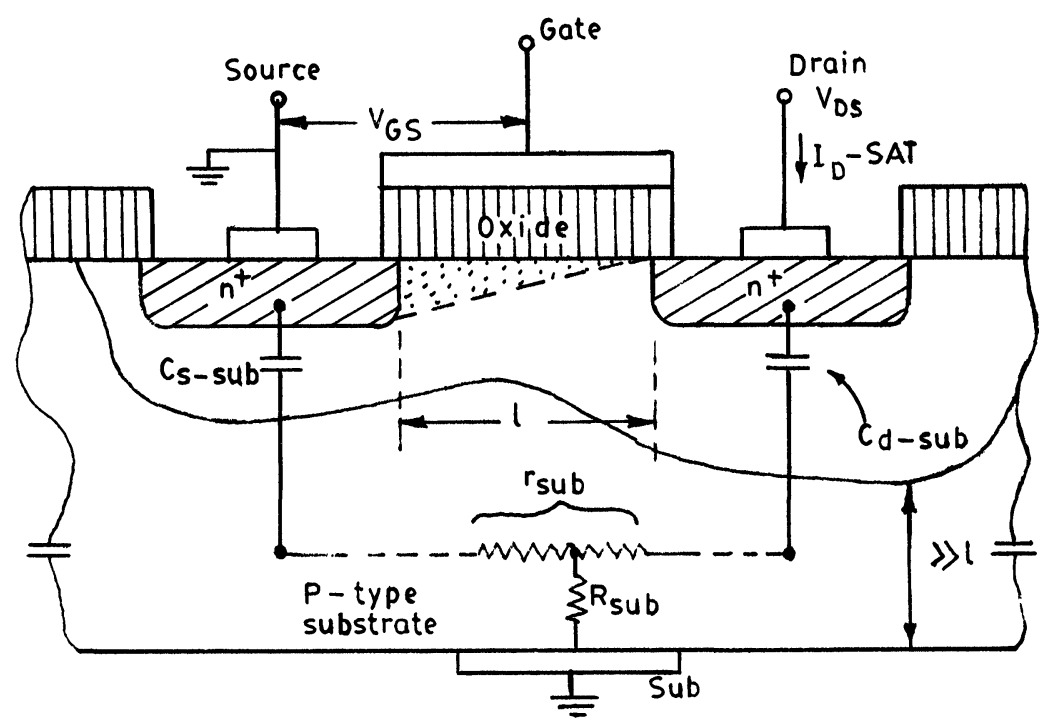

FIGURE 2 Schematic diagram of the MOST showing the origin of extrinsic networks.

This eqn. is extensively used for the d.c. and low frequency analysis of MOST (Metal Oxide Semiconductor Transistor) characteristics. The inversion layer charge $\mathrm{Q}_{\mathrm{n}}$ is given as

$$
\begin{aligned}
\mathrm{Q}_{\mathrm{n}} & =\mathrm{C}_{\mathrm{o}}\left(\mathrm{VG}_{\mathrm{s}}-\mathrm{VS}_{\mathrm{o}}-\mathrm{A} \sqrt{\phi+\mathrm{V}_{\mathrm{x}}}-\mathrm{V}_{\mathrm{x}}\right) \\
& =\mathrm{C}_{\mathrm{o}}\left(\mathrm{V}_{\mathrm{G}}-\mathrm{V}_{\mathrm{x}}-\mathrm{A} \sqrt{\phi+\mathrm{V}_{\mathrm{x}}}+\mathrm{A} \sqrt{\phi}\right)
\end{aligned}
$$

Where $\mathrm{V}_{\mathrm{G}}=\mathrm{VG}_{\mathrm{s}}-\mathrm{V}_{\mathrm{T}}$

$$
\begin{aligned}
\mathrm{V}_{\mathrm{T}} & =\mathrm{VS}_{\mathrm{o}}+\mathrm{A} \sqrt{\phi} \\
\phi & =\phi_{\mathrm{o}}+\mathrm{V}_{\mathrm{Sub}}
\end{aligned}
$$

$\mathrm{VS}_{\mathrm{o}}$ represents that part of the threshold voltage that arises due to band bending, metal semiconductor work function difference, and the presence of possible oxide charge near the semiconductor surface. The parameter A represents the substrate doping effects. A new function $\mathrm{F}$ can be defined as

$$
F=\int_{0}^{V_{x}} f\left(V_{x}\right) d x
$$

Where $f\left(V_{x}\right)=Q_{n} / C_{o}$

By (2) \& (4), F may be expressed as:

$$
\mathrm{F}=\mathrm{V}_{\mathrm{G}} \mathrm{V}_{\mathrm{x}}-\frac{1}{2} \mathrm{~V}_{\mathrm{x}}^{2}-\frac{2}{3} \mathrm{~A}\left[(\phi)+\mathrm{V}_{\mathrm{x}}\right]^{3 / 2}+\frac{2}{3} \mathrm{~A} \phi^{3 / 2}+\mathrm{A} \sqrt{\phi} \mathrm{V}_{\mathrm{x}}
$$


Combining eqns. (1) \& (4), the current I may be expressed as

$$
\mathrm{I}=\beta \frac{\partial \mathrm{F}}{\partial \mathrm{x}}=\mathrm{g}_{\mathrm{mo}}\left(\frac{1}{\mathrm{~V}_{\mathrm{G}}} \frac{\partial \mathrm{F}}{\partial \mathrm{x}}\right)
$$

where $\beta=\frac{\mathrm{Z}}{\mathrm{l}} \mathrm{C}_{\mathrm{o}} \bar{\mu}_{\mathrm{s}}$

$$
\begin{aligned}
\mathrm{g}_{\mathrm{mo}} & =\beta \mathrm{V}_{\mathrm{G}} \\
\mathrm{X} & =\mathrm{x} / \mathrm{l}
\end{aligned}
$$

For linear approximation of the device, the small signal alternating currents and voltages may be considered to be superimposed on the mean dc levels at every point in the active channel region maintaining the overall behavior as dictated by eqn. (6). This situation can, however, arise due to three independent modes of

\section{TABLE I}

\begin{tabular}{|c|c|c|}
\hline System description & Differential equations & Boundary equations \\
\hline $\begin{array}{l}\text { A double trans- } \\
\text { mission line } \\
\text { Fig. 3(a) }\end{array}$ & $\begin{aligned} \mathrm{i}_{\mathrm{x}} & =-\frac{1}{\varphi_{\mathrm{o}}} \frac{\partial\left(\psi_{\mathrm{s}}=\psi_{\mathrm{x}}\right)}{\partial \mathrm{x}} \frac{\partial^{2}\left(\psi_{\mathrm{s}}-\psi_{\mathrm{x}}\right)}{\partial \mathrm{x}^{2}} \\
& =\varphi_{\mathrm{o}} \frac{\partial}{\partial \mathrm{t}}\left\{\mathrm{C}\left(\psi_{\mathrm{s}}-\psi_{\mathrm{x}}\right)-\mathrm{C}^{\prime} \psi_{\mathrm{x}}\right\}\end{aligned}$ & $\begin{aligned} \text { When } \mathrm{X} & =0 \\
\psi_{\mathrm{x}} & =0 \\
\text { When } \mathrm{X} & =1 \\
\psi_{\mathrm{x}} & =\gamma \psi_{\mathrm{s}}\end{aligned}$ \\
\hline $\begin{array}{l}\text { Gate excitation of } \\
\text { MOSTS Fig. } 4(a)\end{array}$ & $\begin{aligned} \mathrm{i}_{\mathrm{x}} & =-\mathrm{g}_{\mathrm{mo}} \frac{\partial\left(\mathrm{V}_{\mathrm{g}}-\mathrm{U}_{\mathrm{x}}\right)}{\partial \mathrm{x}} \frac{\partial^{2}\left(\mathrm{~V}_{\mathrm{g}}-\mathrm{U}_{\mathrm{x}}\right)}{\partial \mathrm{x}^{2}} \\
& =\frac{\mathrm{C}_{\mathrm{ox}}}{\mathrm{g}_{\mathrm{mo}}}\left[\frac{\partial}{\partial \mathrm{t}}\left\{\eta_{1}\left(\mathrm{~V}_{\mathrm{g}}-\mathrm{U}_{\mathrm{x}}\right)-\eta_{2} \mathrm{U}_{\mathrm{x}}\right\}\right]\end{aligned}$ & $\begin{aligned} \text { When } \mathrm{X} & =0 \\
\mathrm{U}_{\mathrm{x}} & =0 \\
\text { When } \mathrm{X} & =1 \\
\mathrm{U}_{\mathrm{x}} & =\gamma \mathrm{V}_{\mathrm{g}}\end{aligned}$ \\
\hline $\begin{array}{l}\text { Substrate excitation } \\
\text { of MOSTS Fig. } 4(\mathrm{~b})\end{array}$ & $\begin{aligned} \mathrm{i}_{\mathrm{x}} & =-\mathrm{g}_{\mathrm{mo}} \frac{\partial\left(\mathrm{V}_{\mathrm{sub}}-\mathrm{U}_{\mathrm{x}}\right)}{\partial \mathrm{x}} \frac{\partial^{2}\left(\mathrm{~V}_{\mathrm{sub}}-\mathrm{U}_{\mathrm{x}}\right)}{\partial \mathrm{x}^{2}} \\
& =\frac{\mathrm{C}_{\mathrm{ox}}}{\mathrm{g}_{\mathrm{mo}}}\left\{\frac{\partial}{\partial \mathrm{t}} \eta_{2}\left(\mathrm{~V}_{\mathrm{sub}}-\mathrm{U}_{\mathrm{x}}\right)-\eta_{1} \mathrm{U}_{\mathrm{x}}\right\}\end{aligned}$ & $\begin{aligned} \text { When } \mathrm{X}= & 0 \\
\mathrm{U}_{\mathrm{x}}= & 0 \\
\text { When } \mathrm{X}= & 1 \\
\mathrm{U}_{\mathrm{x}}= & (1-\gamma) \\
& \mathrm{V}_{\text {sub }}\end{aligned}$ \\
\hline $\begin{array}{l}\text { A single RC trans- } \\
\text { mission line Fig. } 3(\mathrm{~b})\end{array}$ & $\begin{aligned} \mathrm{i}_{\mathrm{x}} & =-\frac{1}{\varphi_{\mathrm{o}}} \frac{\partial\left(\psi_{\mathrm{s}}-\psi_{\mathrm{x}}\right)}{\partial \mathrm{x}} \frac{\partial^{2}\left(\psi_{\mathrm{s}}-\psi_{\mathrm{x}}\right)}{\partial \mathrm{x}^{2}} \\
& =\varphi_{\mathrm{o}}\left(\mathrm{C}+\mathrm{C}^{\prime}\right) \frac{\partial}{\partial \mathrm{t}}\left(\psi_{\mathrm{s}}-\psi_{\mathrm{x}}\right)\end{aligned}$ & $\begin{aligned} \text { When } \mathrm{X} & =0 \\
\psi_{\mathrm{x}} & =0 \\
\text { When } \mathrm{X} & =1 \\
\psi_{\mathrm{x}} & =\psi_{\mathrm{s}}\end{aligned}$ \\
\hline $\begin{array}{l}\text { Gate and substrate } \\
\text { combined excitation } \\
\text { of MOSTS Fig. } 4(\mathrm{c})\end{array}$ & $\begin{aligned} \mathrm{i}_{\mathrm{x}} & =-\mathrm{g}_{\mathrm{mo}} \frac{\partial\left(\mathrm{V}_{\mathrm{s}}-\mathrm{U}_{\mathrm{x}}\right)}{\partial \mathrm{x}} \frac{\partial^{2}\left(\mathrm{~V}_{\mathrm{s}}-\mathrm{U}_{\mathrm{x}}\right)}{\partial \mathrm{x}^{2}} \\
& =\frac{\mathrm{C}_{\mathrm{ox}}}{\mathrm{g}_{\mathrm{mo}}}\left(\eta_{1}+\eta_{2}\right) \frac{\partial}{\partial \mathrm{t}}\left(\mathrm{V}_{\mathrm{s}}-\mathrm{U}_{\mathrm{x}}\right)\end{aligned}$ & $\begin{aligned} \text { When } \mathrm{X} & =0 \\
\mathrm{U}_{\mathrm{x}} & =0 \\
\text { When } \mathrm{X} & =1 \\
\mathrm{U}_{\mathrm{x}} & =\mathrm{V}_{\mathrm{s}}\end{aligned}$ \\
\hline
\end{tabular}

Comparison of the differential equations representing the device and the RC transmission line analogs 
signal excitation: gate excitation, substrate excitation, and combined gate and substrate excitation. Table 1 shows the RC transmission line analogs.

\section{RC TRANSMISSION LINE ANALOG}

The small-signal differential equations of the MOST under different modes of excitation are analogous to those of a double RC transmission line except for the complication arising due to the double variables $v_{x}$ and $U_{x}$. The differential equation of a double RC line having uniform resistance but nonuniform capacitance per unit length, can be written with reference to the Fig. 3 as

$$
\mathrm{i}_{\mathrm{x}}=\frac{1}{\varphi \mathrm{o}} \frac{\partial \psi_{\mathrm{x}}}{\partial \mathrm{X}}
$$

and $\frac{\partial^{2}\left(\psi_{\mathrm{s}}-\psi_{\mathrm{x}}\right)}{\partial \mathrm{X}^{2}}=\varphi \mathrm{o}\left\{\mathrm{C}(\mathrm{x})-\frac{\partial}{\partial \mathrm{t}}\left(\psi_{\mathrm{s}}-\psi_{\mathrm{x}}\right)-\mathrm{C}(\mathrm{x})^{\prime} \frac{\partial}{\partial \mathrm{t}}\left(\psi_{\mathrm{x}}\right)\right\}$

For convenience, the $\mathrm{RC}$ lines have been considered to be a unit length having uniform resistance $\varphi_{\mathrm{o}}$ and non-uniform capacitances $\mathrm{C}(\mathrm{x}) \& \mathrm{C}(\mathrm{x})^{\prime}$. Two excitation voltages $\psi_{\mathrm{s}}$ and $\gamma \psi_{\mathrm{x}}$ are used for the analog RC line because of the particular boundary conditions of the actual device.

From Table I, it should be noted that the voltage distribution $\psi_{\mathrm{x}}$ of the RC line
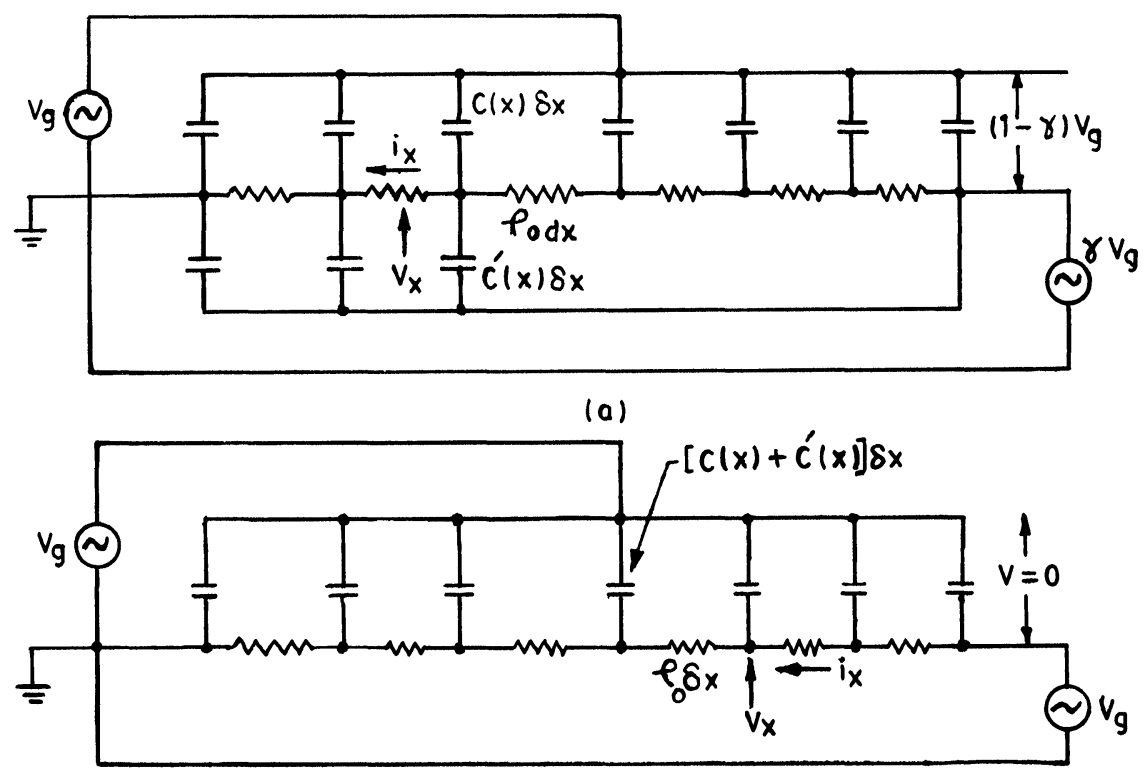

(b)

FIGURE 3a A double RC transmission line with twin voltage excitations.

FIGURE 3b A single RC transmission line with twin voltage excitations. 


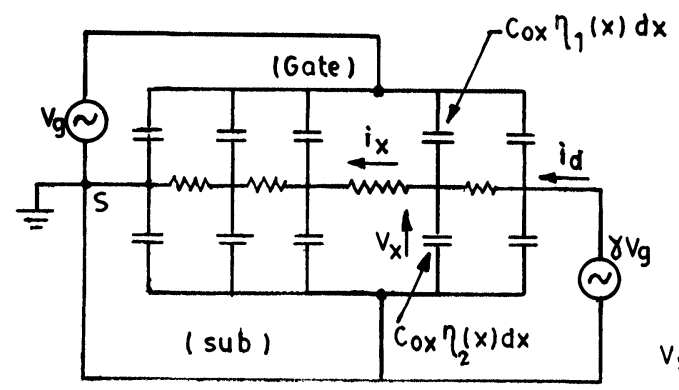

Fig: $4(a)$

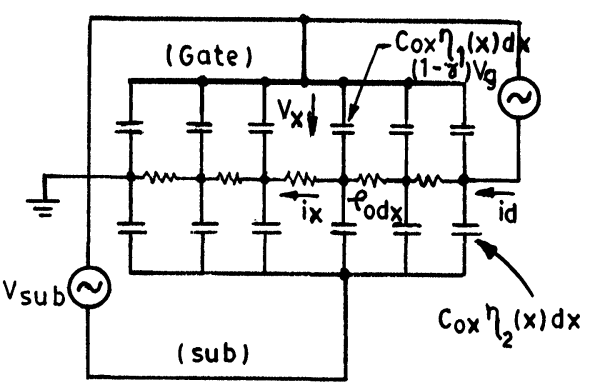

Fig: $4(b)$

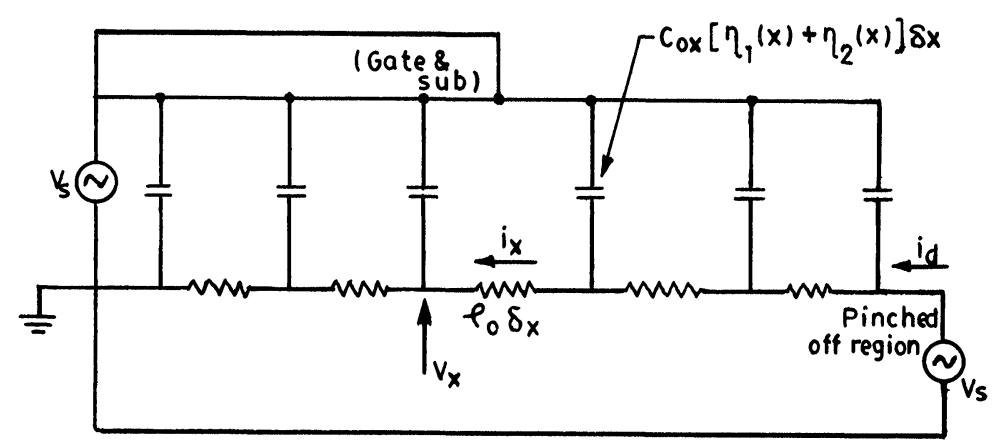

Fig: $4(c)$

FIGURE 4a RC double transmission analogs of the MOST under gate excitation.

FIGURE 4b Under substrate excitation.

FIGURE 4c Under the gate-substrate excitation.

is analogous to the voltage distribution $\mathrm{V}_{\mathrm{x}}$, and not to the actual channel voltage distribution $\mathrm{V}_{\mathrm{x}}$, as capacitance distributions $\mathrm{C}(\mathrm{x})$ and $\mathrm{C}(\mathrm{x})^{\prime}$ are analogous to $\mathrm{Co}_{\mathrm{x}}$ $\eta_{1}(\mathrm{x})$ and $\mathrm{Co}_{\mathrm{x}} \eta_{2}(\mathrm{x})$ respectively. The formal expressions are:

$$
\begin{aligned}
\eta_{1} & =1+\left(1+\mathrm{a}_{\mathrm{x}}\right) \frac{\mathrm{V}_{\mathrm{x}}}{\mathrm{f}\left(\mathrm{V}_{\mathrm{x}}\right)} \\
\eta_{2} & =\left(1+\mathrm{a}_{\mathrm{x}}\right) \frac{\mathrm{V}_{\mathrm{G}}-\mathrm{V}_{\mathrm{x}}}{\mathrm{f}\left(\mathrm{V}_{\mathrm{x}}\right)}-1 \\
\&\left(\eta_{1}+\eta_{2}\right) & =\left(1+\mathrm{a}_{\mathrm{x}}\right) \frac{\mathrm{V}_{\mathrm{G}}}{\mathrm{f}\left(\mathrm{V}_{\mathrm{x}}\right)}
\end{aligned}
$$

A comparison of the current equation for the actual device and the RC analogs reveals that the currents are identical in both cases. This fact makes it possible to obtain all the terminal admittances of the MOST in exact terms of those of the analog RC transmission line. 


\section{LOW FREQUENCY CHARACTERISTICS}

The separate RC analog representations are shown in Fig. 4, which correspond to the three modes of device excitations from Table I. The calculation of the $y$-parameters of the intrinsic MOST has been carried out on the basis of the validity of the equivalent $\mathrm{RC}$ transmission line analogs.

In Fig. 5, qualitative charge storage representation for all the three modes of excitations has been shown.

\section{HF CHARACTERISTICS INCLUDING SUBSTRATE EFFECTS}

\section{A. Intrinsic Y-Parameters}

In the general case of the MOST structure including the substrate control effects, there are three different modes of signal excitation as considered earlier in section II. Each mode of operation is characterized by its specific set of differential eqns. (Table I) that must be solved for the derivation of the appropriate intrinsic admittance parameters. Among the three modes of operation, the combined gate substrate excitation mode can be treated in terms of an $\mathrm{RC}$ transmission line having a single non-uniform capacitance distribution and a uniform resistance distribution. Determination of the MOST terminal admittances in terms of these analogs is extremely difficult because of the complex nature of the capacitance distributions $\eta_{1}(\mathrm{x})$ and $\eta_{2}(\mathrm{x})$ at all bias levels and because of the subsequent tedious steps involved in the calculation of the overall transmission matrix of the $\mathrm{RC}$ line. Using piecewise uniformity approximation of effective uniform capacitances $\mathrm{C}_{\mathrm{G}}$ and $\mathrm{C}_{\text {SUB }}$ (Table II) assumed for the actual nonuniform capacitance distributions, simplicity in results can be obtained.

The case of gate excitation in the common source and substrate configuration has been analysed on the basis of effective uniform capacitances in Appendix II. This has yielded the basic admittance parameters $Y_{11}, Y_{21}, Y_{31}$ where 1, 2, 3 refer

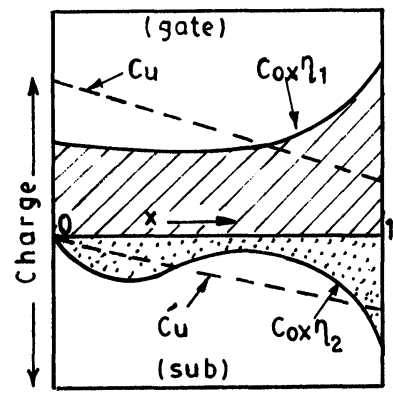

(a)
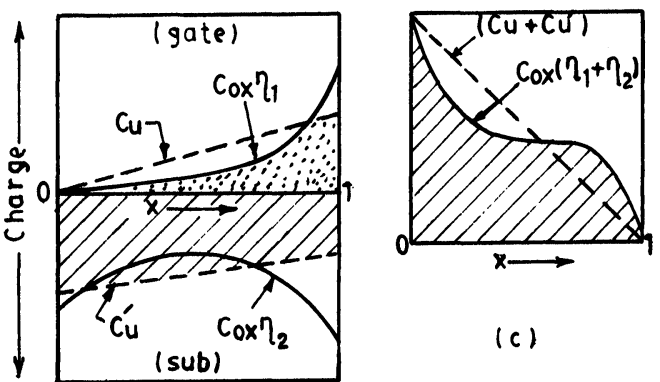

(c)

FIGURE 5 Qualitative charge storage representation for the: a) Gate excitation; b) The substrate excitation; c) Gate-substrate excitations. 
TABLE II

Device capacitances and double RC line approximations

\begin{tabular}{|c|c|c|c|c|}
\hline \multicolumn{2}{|l|}{ Capacitance } & Actual expression & $\begin{array}{l}\text { Uniform C } \\
\text { approximation }\end{array}$ & \multirow{2}{*}{$\begin{array}{l}\begin{array}{l}\text { Effective } \\
\text { uniform } C\end{array} \\
\frac{\mathrm{C}_{G}}{(1-\gamma / 2)}\end{array}$} \\
\hline & $\begin{array}{l}\text { General } \\
\text { case }\end{array}$ & $\begin{array}{l}\operatorname{Cox}\left[\left\{\left(1+\frac{\gamma}{2}-\frac{5}{6} \gamma^{2}\right)\right.\right. \\
\left.\left.+\mathrm{a} \gamma\left(1-\frac{5}{6} \gamma\right)+\mathrm{b}\left(\frac{1}{3}-\frac{7 \gamma}{30}\right)\right\}\right]\end{array}$ & $\mathrm{C}_{\mathrm{u}}\left(1-\frac{\gamma}{2}\right)$ & \\
\hline $\begin{array}{l}\text { CG } \\
\text { gate } \\
\text { input }\end{array}$ & $\begin{array}{l}\text { When } \\
\gamma=1 \\
\text { and } \\
a \rightarrow 0\end{array}$ & $\frac{2}{3} \operatorname{Cox}$ & $\frac{1}{2} C_{u}$ & $\frac{4}{3} \operatorname{Cox}$ \\
\hline & $\begin{array}{l}\text { General } \\
\text { case }\end{array}$ & $\begin{array}{l}\operatorname{Cox}\left[\left(\frac{1}{6}+\frac{2}{3} \gamma-\frac{5}{6} \gamma^{2}\right)+\mathrm{a}\left\{\left(\frac{2}{3}+\frac{6}{2}\right)\right.\right. \\
\left.\left.+\left(\frac{7}{6}+\frac{2}{5} \mathrm{~b}\right) \gamma-\left(\frac{5}{6}+\frac{7}{30} \mathrm{~b}\right) \gamma^{2}\right\}\right]\end{array}$ & $\mathrm{C}_{\mathrm{u}}^{\prime} \frac{(1+\gamma)}{2}$ & $\frac{C_{\text {sub }}}{\frac{1}{2}(1+\gamma)}$ \\
\hline $\begin{array}{l}\mathrm{C}_{\text {sUB }} \\
\text { sub- } \\
\text { strate } \\
\text { input }\end{array}$ & $\begin{array}{l}\text { When } \\
\gamma=1 \\
\text { and } \\
a \rightarrow 0\end{array}$ & 0 & 0 & 0 \\
\hline & $\begin{array}{l}\text { General } \\
\text { case }\end{array}$ & $\operatorname{Cox}\left[\frac{2}{3}-a\left(\frac{2}{3}+\frac{b}{2}\right)\right]$ & $\frac{1}{2}\left(C_{u}+C_{u}^{\prime}\right)$ & $2 \mathrm{C}_{\text {(G-SUB) }}$ \\
\hline $\begin{array}{l}\mathrm{C}_{[G-S u B]} \\
\text { gate and } \\
\text { substrate } \\
\text { input }\end{array}$ & $\begin{array}{l}\text { When } \\
\gamma=1 \\
\text { and } \\
\mathrm{a}=0\end{array}$ & $\frac{2}{3} \operatorname{Cox}$ & $\frac{1}{2} C_{u}$ & $\frac{4}{3} \operatorname{Cox}$ \\
\hline $\mathrm{C}_{\mathrm{G}-\text { suB }}$ & $\begin{array}{l}\text { General } \\
\text { case }\end{array}$ & $\operatorname{Cox}(1-\gamma)\left\{\left(\frac{1}{2}+\frac{16}{15} \gamma\right)+\mathrm{a} \gamma\left(\frac{16}{15}+\frac{7}{30} \mathrm{~b}\right)\right.$ & $\mathrm{C}_{\mathrm{u}} \frac{(1-\gamma)}{2}$ & - \\
\hline$\stackrel{\mathrm{C}_{\text {SUB G }}}{\leftarrow}$ & $\begin{array}{l}\text { General } \\
\text { case }\end{array}$ & $\begin{array}{l}\operatorname{Cox} \gamma\left[\frac{5}{6}(1-\gamma)+\mathrm{a}\left\{\left(\frac{4}{3}-\frac{5}{6} \gamma\right)\right.\right. \\
\left.\left.+\mathrm{b}\left(\frac{1}{2}-\frac{7}{30} \gamma\right)\right\}\right]\end{array}$ & $\mathrm{C}_{\mathrm{u}}^{\prime} \frac{\gamma}{2}$ & - \\
\hline$\simeq \frac{\mathrm{A}}{2 \sqrt{b}}$ & $\overline{\overline{\gamma \mathbf{A}_{\mathrm{G}}}} ; \mathrm{b}$ & $\frac{\gamma \mathbf{V}_{\mathrm{G}}}{2\left(\phi+\gamma \mathbf{V}_{\mathrm{G}}\right)} ; \gamma=\left(1+\frac{\mathrm{A}}{2 \sqrt{\phi}}\right)^{-1}$ & & \\
\hline
\end{tabular}

to gate, drain and substrate terminals respectively. Simplified versions of these admittances are given in Table IV, which clearly indicates the influence of the substrate properties on the device high frequency performance. Of particular interest is the reduction of the input conductance (real part of $Y_{11}$ ), manifested by a higher value of the constant $d$ than usual (Table III), and the reduction in the phase lag of $Y_{21}$ and possible increase in the magnitude of $Y_{21}$ for values of $\delta$ larger than the constant $1 / \mathrm{s}$. The short-circuited condition between source and substrate 
TABLE III

Admittance parameters including substrate effects

(Excitation: gate input: source and substrate common)*

\begin{tabular}{|c|c|c|}
\hline Admittance & High frequency expressions (approx.) & $\begin{array}{l}\text { Low frequency } \\
\text { (approx.) }\end{array}$ \\
\hline $\begin{array}{l}Y_{11} \\
\text { gate input }\end{array}$ & $\begin{array}{l}\frac{\mathrm{j} \omega \mathrm{C}_{\mathrm{G}}}{1+\mathrm{j} \frac{\omega \mathrm{C}_{\mathrm{G}}}{\mathrm{dgm} m_{\mathrm{o}}}} \\
\text { where } \\
\mathrm{d}=\frac{6(2-\gamma)}{1-\frac{\mathrm{C}_{u}^{\prime}}{\mathrm{C}_{u}}\left(\frac{\gamma}{2-\gamma}\right)} \\
\text { alternatively } \\
\mathrm{d}=\frac{6(2-\gamma)}{1-\frac{\mathrm{C}_{\mathrm{SuB}}}{\mathrm{C}_{\mathrm{G}}}\left(\frac{\gamma}{1+\gamma}\right)} \\
\text { and } \\
\mathrm{C}_{\mathrm{G}}=\mathrm{C}_{\mathrm{u}}\left(1-\frac{\gamma}{2}\right)\end{array}$ & $\mathrm{j} \omega \mathrm{C}_{\mathrm{G}}+\omega^{2} \mathrm{C}_{\mathrm{G}}^{2}\left(\frac{1}{\operatorname{dgm}_{\mathrm{o}}}\right)$ \\
\hline $\begin{array}{l}Y_{21} \\
\text { drain } \\
\text { transfer }\end{array}$ & $\begin{array}{l}\gamma \mathrm{gm}_{\mathrm{o}} \frac{(1+\mathrm{j} \delta \omega \tau)}{\left(1+\mathrm{j} \frac{\omega \tau}{\mathrm{s}}\right)} \exp \left\{\frac{-\mathrm{jk}_{\mathrm{o}} \omega \tau}{\mathrm{s}}\right\} \\
\text { where } \\
\mathrm{K}_{\mathrm{o}} \simeq 0.6, \mathrm{~s} \simeq 4.72, \gamma=\frac{1}{2} \frac{\left(\mathrm{C}_{\mathrm{u}}+\mathrm{C}_{\mathrm{u}}^{\prime}\right)}{\mathrm{g}_{\mathrm{mo}}} \\
\text { and } \\
\delta=1-\frac{1}{\gamma}\left(\frac{\mathrm{Cu}}{\mathrm{C}_{\mathrm{u}}+\mathrm{C}_{\mathrm{u}}^{\prime}}\right) \\
\text { alternatively } \\
\delta=1-\frac{1}{\gamma} \frac{\mathrm{C}_{\mathrm{G}}}{\left(\mathrm{C}_{\mathrm{G}}+\frac{2-\gamma}{1+\gamma} \mathrm{C}_{\mathrm{SUB}}\right)} \\
\text { and } \\
\tau=\frac{1}{\operatorname{gm}_{\mathrm{o}}}\left(\frac{\mathrm{C}_{\mathrm{G}}}{2-\gamma}+\frac{\mathrm{C}_{\mathrm{SUB}}}{1+\gamma}\right)\end{array}$ & $\begin{array}{l}\gamma \mathrm{g}_{\mathrm{mo}}=\mathrm{j} \omega \mathrm{C}_{21} \\
\text { where } \\
\mathrm{C}_{21}=\frac{1}{2} \mathrm{C}_{\mathrm{u}}\left(1-\frac{2 \gamma}{3}\right)-\frac{1 \gamma}{3} \mathrm{C}_{\mathrm{u}}^{\prime} \\
\text { alternatively, } \\
\mathrm{C}_{21}=\frac{3-2 \gamma}{2-\gamma}\left(\frac{\mathrm{C}_{\mathrm{G}}}{3}\right) \\
\quad-\left(\frac{\gamma}{1+\gamma}\right) \frac{2}{3} \mathrm{C}_{\text {SUB }}\end{array}$ \\
\hline $\begin{array}{l}\mathrm{Y}_{31} \\
\text { substrate } \\
\text { transfer }\end{array}$ & $\begin{array}{l}-\mathrm{j} \omega \mathrm{C}_{\mathrm{u}}^{\prime} \frac{\gamma}{2}+\frac{\omega^{2} \mathrm{C}_{\mathrm{u}}^{\prime}}{12 \mathrm{gm}_{\mathrm{o}}}\left\{\mathrm{Cu}-\frac{\gamma}{2}\left(\mathrm{C}_{\mathrm{u}}+\mathrm{C}_{\mathrm{u}}^{\prime}\right)\right\} ; \\
\text { alternatively } \\
-\mathrm{j} \omega \frac{\gamma}{1+\gamma} \mathrm{C}_{\mathrm{SUB}}+\frac{\omega^{2}}{6 \mathrm{gm}_{\mathrm{o}}}\left(\frac{\mathrm{C}_{\mathrm{SUB}}}{1+\gamma}\right)\left\{\mathrm{C}_{\mathrm{G}}-\frac{\gamma}{1+\gamma} \mathrm{C}_{\mathrm{SUB}}\right\}\end{array}$ & $\begin{array}{l}-\omega \mathrm{C}_{\mathrm{u}}^{\prime} \frac{\gamma}{2} \\
\text { alternatively } \\
-\mathrm{j} \omega \frac{1}{\gamma+1} \mathrm{C}_{\mathrm{SUB}}\end{array}$ \\
\hline
\end{tabular}

${ }^{*}$ For substrate excitation case substrate $\rightarrow$ gate, $\mathrm{C}_{\mathrm{u}} \rightarrow \mathrm{C}_{\mathrm{u}}^{\prime}, \mathrm{C}_{\mathrm{G}} \rightarrow \mathrm{C}_{\mathrm{SUB}}$ and vice-versa and $\gamma$ is replaced by $(1-\gamma)$ 
TABLE IV

Admittances when substrate resistivity effects are negligible assumption forward transfer admittance

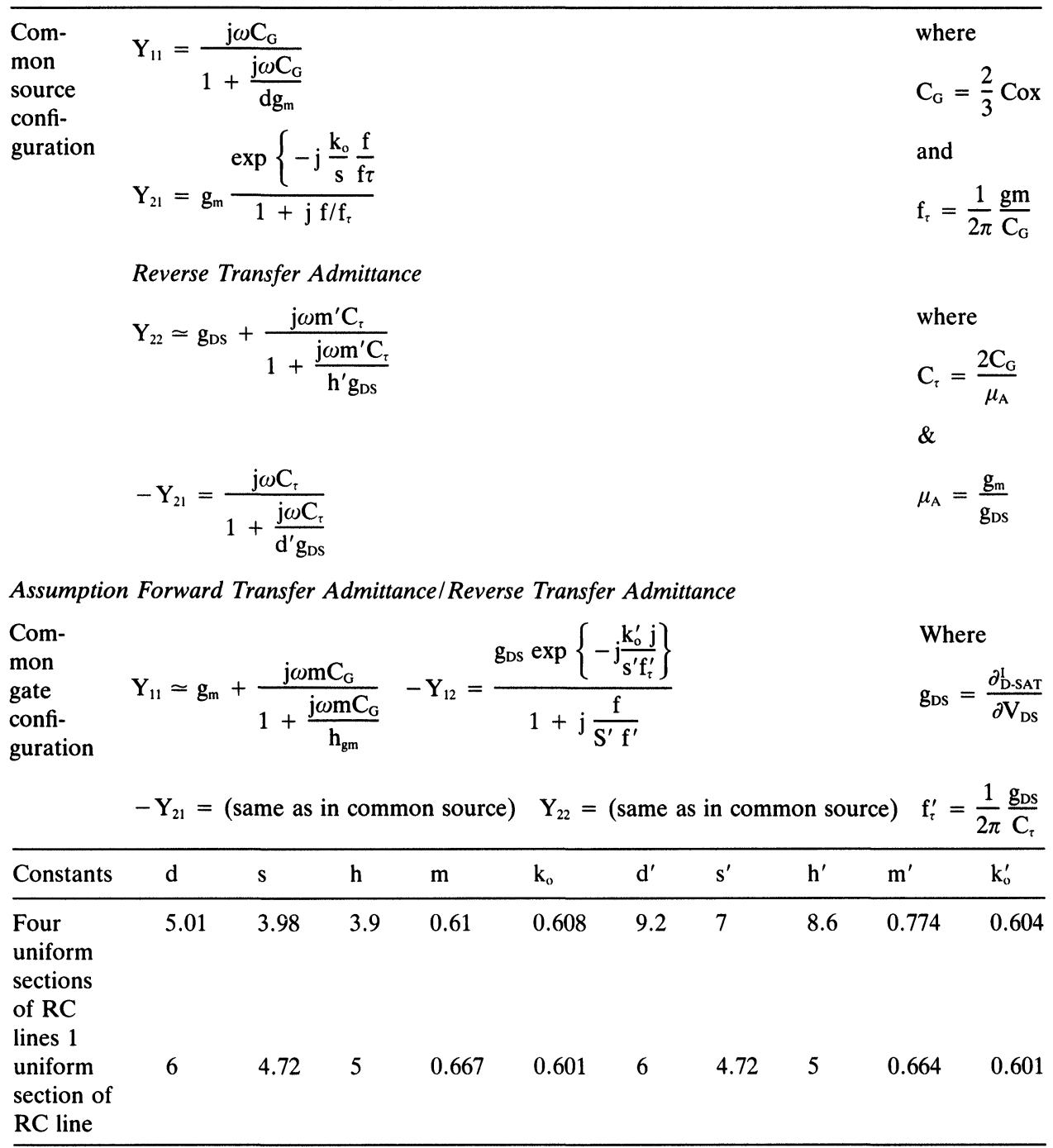

implies that ideally there is no effect of the admittance $Y_{31}$ on the device performance. In practice, however, the presence of a small bulk substrate resistance can cause an indirect excitation of the substrate, which can modify the overall device characteristics to a certain extent. To appreciate these interactions, it is therefore necessary to know the three basic Y-parameters associated with the substrate terminal in the common gate-source configuration. These can be obtained with reference to Table III simply by interchanging the symbols $C_{u}$ for $C_{u}^{\prime}$ and $C_{\text {SUB }}$ for $\mathrm{C}_{\mathrm{G}}$, and vice versa, and replacing $\gamma$ by $(1-\gamma)$ appearing in the various subsidiary relationship. 
The intrinsic Y-parameters are readily obtainable from the consideration of a single capacitance distribution RC line analog, assuming the idealized ac short circuit condition between the metal gate and the bulk substrate. These results are given in Table III. The magnitudes of the constants $\mathrm{d}, \mathrm{h}, \mathrm{m}$, etc., have been taken to be identical to those of a uniform capacitance RC transmission line analog as given in Table IV. This appears to be a reasonable approximation in view of the expected near-triangular shape of the charge distribution curve when substrate effects are appreciable.

\section{B. Equivalent Circuit Representation:}

In a generalized form of the MOST equivalent circuit the intrinsic device action must be treated as a 3-port, 4-terminal network. A common source equivalent circuit combining the 3-port intrinsic admittance RC-network is given in Fig. 6. The relative magnitudes of the extrinsic resistances, $r_{\text {sub }}$ and $R_{\text {sub }}$, originating from the distributed bulk effects are basically determined by the metallurgical details of the device. For example, if an epitaxial active substrate layer is used on a very low resistivity bulk resistance material, the element $R_{\text {sub }}$ can become entirely negligible, and for all practical purposes a single element small value $r_{\text {sub }}$ can represent the extrinsic substrate effects. Under these circumstances the contribution of the transfer parameters $Y_{13}$ and $Y_{23}$ can be ignored when the source and substrate are short circuited. It should, however, be pointed out that this does not eliminate the physical substrate effects on the parameters $Y_{21}$ and $Y_{11}$.

In the combined common gate-substrate configuration the assumption of an ideal short circuit (a.c.) between the gate and substrate yields the simple 2-port equivalent circuit of Fig. 7 and the Y parameters become those given in Table III. In Fig. 8, parameters associated with the substrate terminal are primed to differentiate them from those associated with the gate terminal.

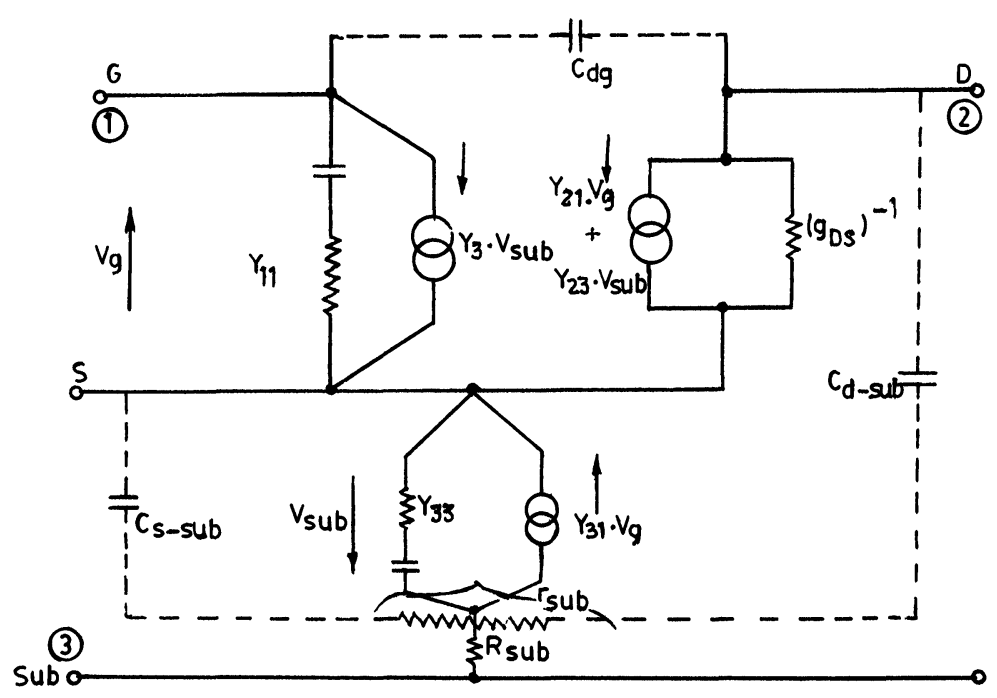

FIGURE 6 A 4-terminal common-source equivalent circuit of MOST including substrate effects. 


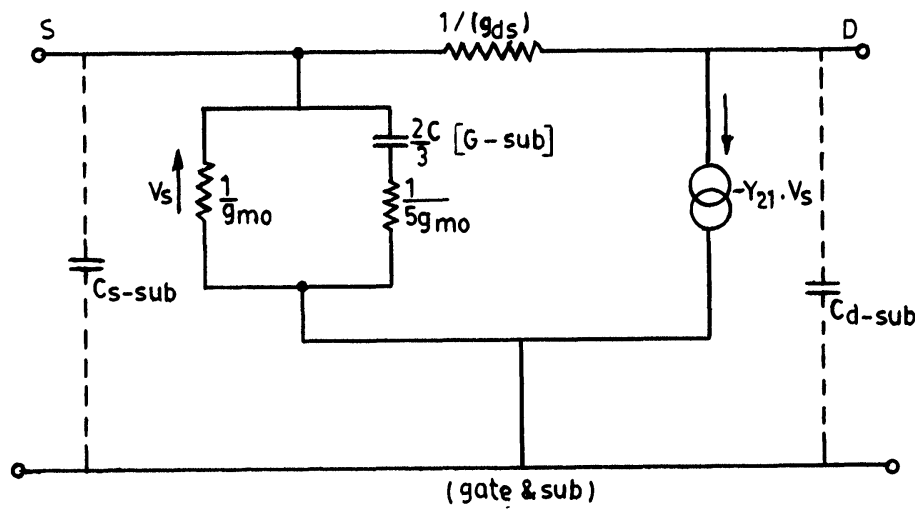

FIGURE 7 A idealised common gate-substrate equivalent circuit in absence of substrate spreading resistance.

\section{DUTTA ROY \& UMESH KUMARS' MODEL ${ }^{5}$ :}

A rational second-order, two-port model for the uniformly distributed $\mathrm{RC}$ structure (URC) is presented that approximates the actual characteristics very closely over a wide frequency range. The model has been applied to predict the behavior of a $\overline{\text { URC }}$ notch network and the results are found to be in close agreement with the exact ones.

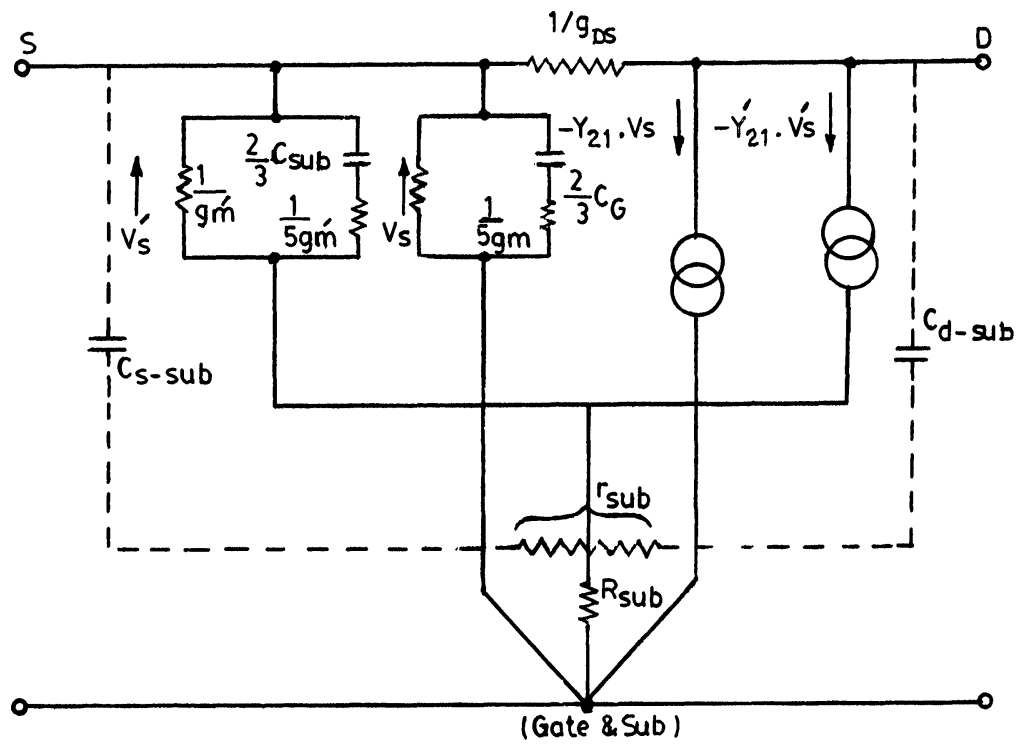

FIGURE 8 A common gate-substrate equivalent circuit including intrinsic and extrinsic substrate effects. 
A uniformally distributed RC two port is characterised by the following immittance matrix.

$R^{ \pm} P^{\mp 1 / 2}\left[\begin{array}{ll}\text { Coth } p^{1 / 2} & \pm \text { Cosech } p^{1 / 2} \\ \pm \operatorname{Cosech} p^{1 / 2} & \text { Coth } P^{1 / 2}\end{array}\right]$

where $\mathrm{p}=\mathrm{SCR}$; the $(+) /(-)$ sign applies to the $\mathrm{Z}(\mathrm{Y})$ matrix; and $\mathrm{R}$ and $\mathrm{C}$ are the total resistance and capacitance of the structure.

\section{THE MODEL AND ITS CHARACTERISTICS}

By series and continued fraction expansions of the Coth and Cosech functions occurring in eqn. (1), and by truncating them at suitable points, eleven first- and second-order rational two-port models of the URC were investigated in the frequency as well as time domains and their characteristics were compared with the exact one. The best performance was obtained from the model obtained through truncation of continued fraction expansions of $Y_{11}$ and $Y_{12}$ at the fourth term resulting in the following $y$-parameters:

$$
\begin{aligned}
& Y_{11}=Y_{22}=\frac{105+45 p+p^{2}}{R(105+10 p)} \\
& Y_{12}=Y_{21}=\frac{-41160+2520 p-77 p^{2}}{R(41160+4340 p)}
\end{aligned}
$$

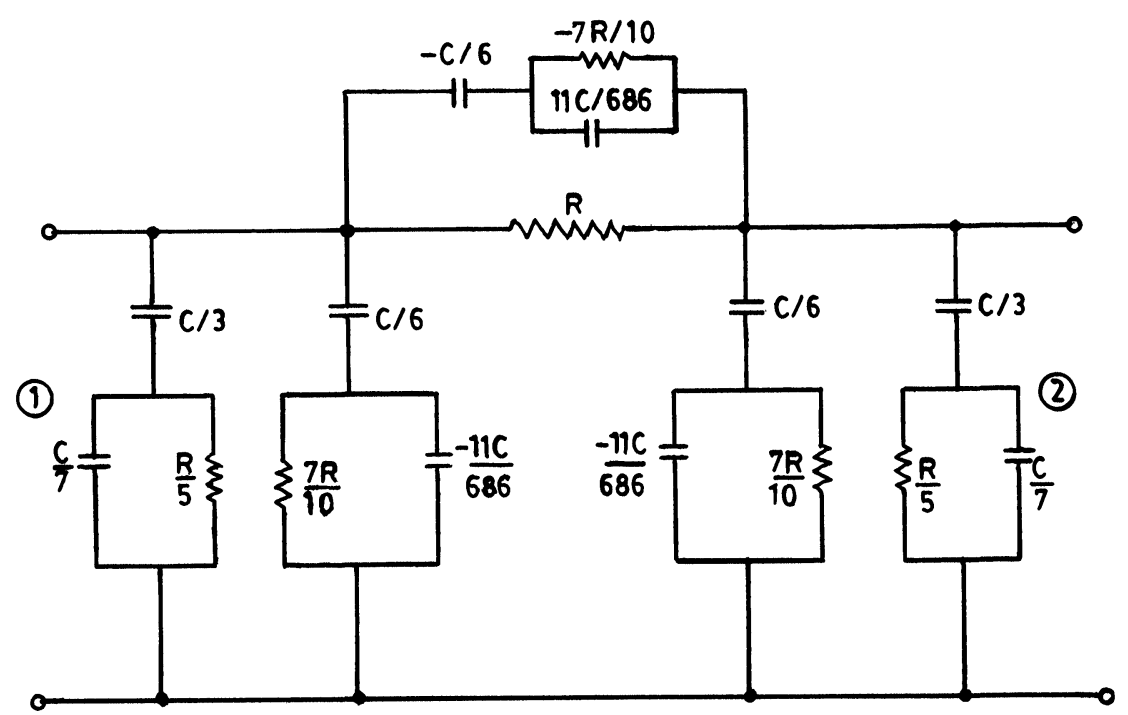

FIGURE 9a Lumped element representation of the model. 


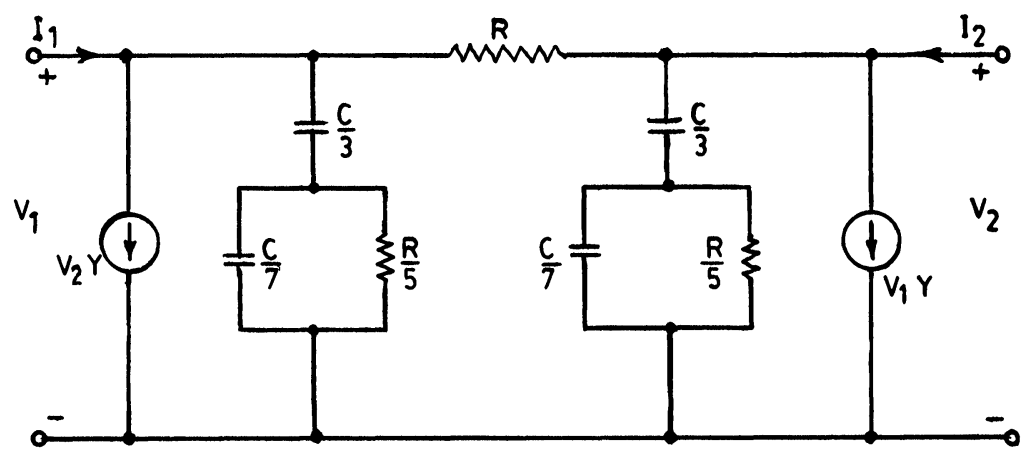

FIGURE 9b Equivalent controlled source representation.

This is a very accurate model both in frequency and time domains. As an aid to computer-aided analysis and design of networks containing the $\overline{\text { URC }}$ structure, a lumped element $\pi$-section representation of the model and its controlled source equivalent structures are given in Figs. 9(a) and 9(b).

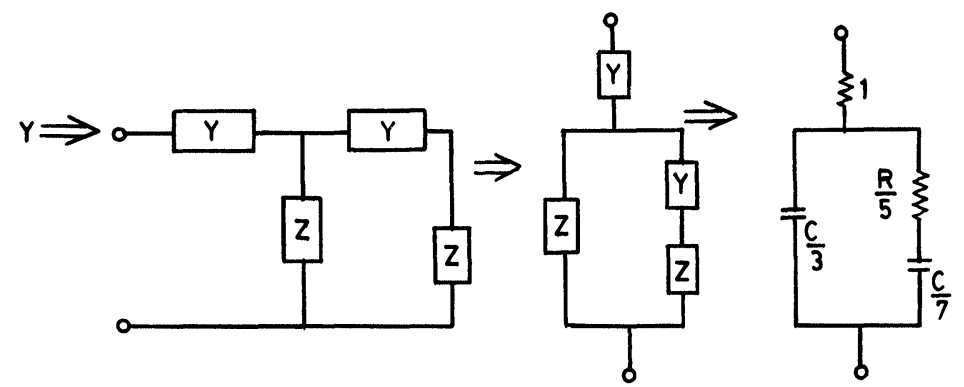

(a)

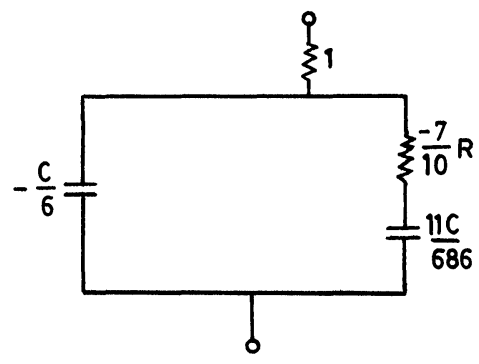

(b)

FIGURE 10 


\section{PROPOSED MODEL}

We have the admittance parameters as follows:

$\mathrm{Y}_{21}=\frac{\mathrm{i}_{\mathrm{d}}}{\mathrm{V}_{\mathrm{g}}}=\mathrm{g}_{\mathrm{o}}\left\{(1-\mathrm{k}) \theta \operatorname{Cosech} \theta+\left(\gamma_{1}-1+\mathrm{k}\right) \theta \operatorname{Coth} \theta\right\}$

here $\gamma_{1}=\frac{\mathrm{V}_{\text {sat }}}{\mathrm{V}_{\mathrm{g}}}$

$\left.\theta \operatorname{coth} \theta=\theta\left(\frac{1}{\theta}+1 /\left(\frac{3}{\theta}+1 /\left(\frac{5}{\theta}+1 /\left(\frac{7}{\theta}\right)\right)\right)\right)\right)$

$\left.\& \theta \operatorname{Cosech} \theta=\theta\left(\frac{1}{\theta}+1 /\left(\frac{-6}{\theta}+1 /\left(\frac{-10}{7 \theta}\right)+1 /\left(\frac{686}{11 \theta}\right)\right)\right)\right)$

here $\theta^{2}=\mathrm{j} \omega\left(\mathrm{C}_{\mathrm{u}}+\mathrm{C}_{\mathrm{u}}^{\prime}\right) \varphi_{\mathrm{o}}$

$$
k=\frac{C_{u}^{\prime}}{\left(C_{u}^{\prime}+C_{u}\right)}
$$

Now $\theta \operatorname{Coth} \theta=\theta\left[\frac{1}{\theta}+\frac{1}{\frac{3}{\theta}+\frac{1}{\frac{5}{\theta}+\frac{1}{7 / \theta}}}\right]$

$$
=1+\frac{1}{\frac{3}{\theta^{2}}+\frac{1}{5+\frac{1}{7 / \theta^{2}}}}
$$

We are taking Y-parameters, so this can be represented as:

$$
Y=Y+\frac{1}{Z+\frac{1}{Y+1 / Z}}
$$

Thus, (See Fig. 10(a)) so in $Y_{21}$ expression we have,

$$
\mathrm{Y}_{21}=\mathrm{g}_{\mathrm{o}}\left\{\left(\gamma_{1}-1+\mathrm{k}\right) \theta \operatorname{coth} \theta+(1-\mathrm{k}) \theta \operatorname{Cosech} \theta\right\}
$$

(a) 


$$
\begin{aligned}
\theta \operatorname{Cosech} \theta & \left.=\theta\left(\frac{1}{\theta}+1 /\left(-\frac{6}{\theta}+1 /\left(-\frac{10}{7 \theta}+1 / \frac{686}{11 \theta}\right)\right)\right)\right) \\
& =\theta\left[1+\frac{1}{\left.-\frac{6}{\theta^{2}}+\frac{1}{-\frac{10}{7}+1 / \frac{686}{11 \theta^{2}}}\right]}\right] \\
\mathrm{Y} & =\mathrm{Y}+\frac{1}{\mathrm{Z}+\frac{1}{\mathrm{Y}+\frac{1}{\mathrm{Z}}}}
\end{aligned}
$$
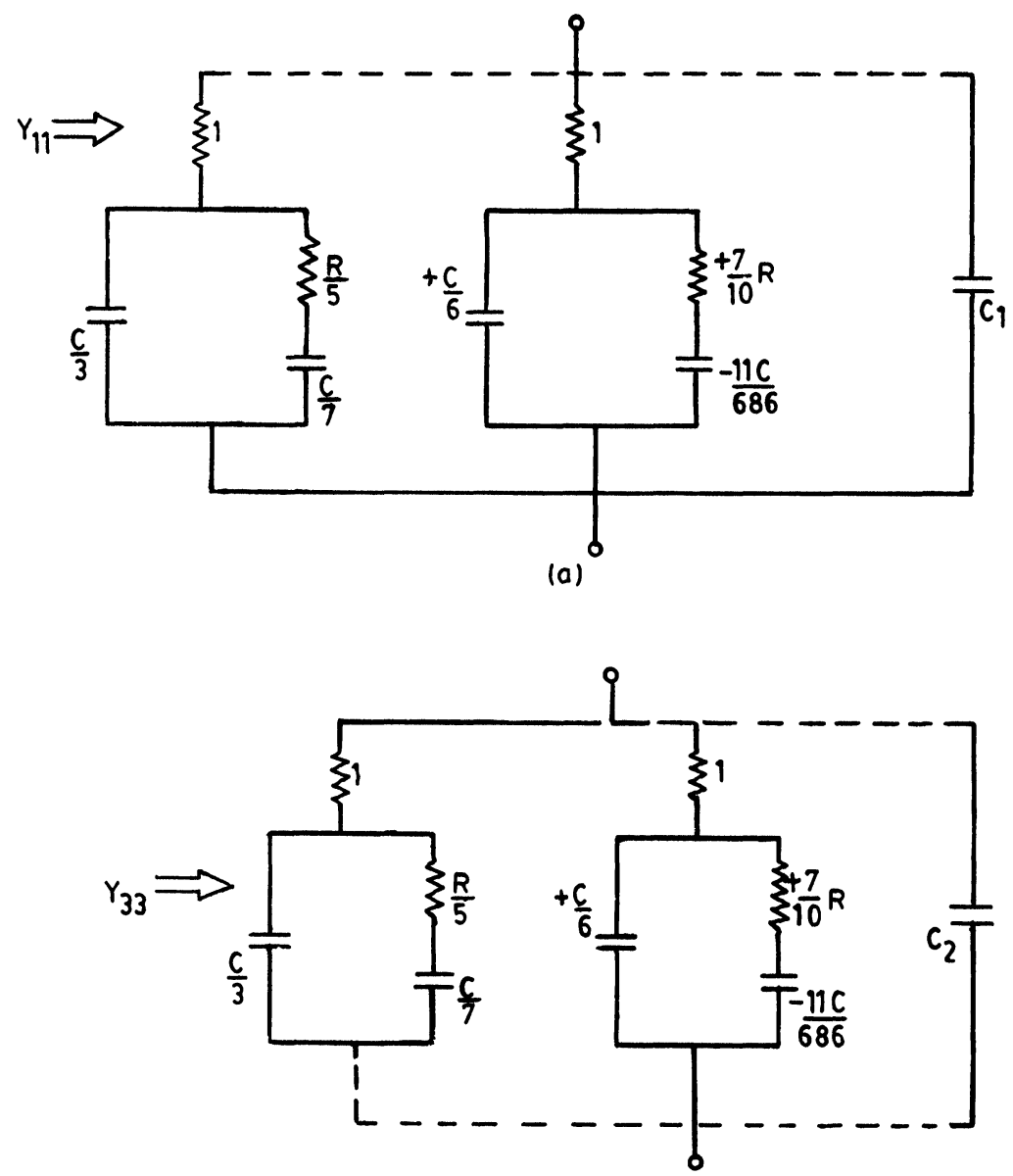

(b)

FIGURE 11 
This can be represented as: (Fig. 10(b), see)

Now $Y_{11}=-\frac{j \omega C_{u}}{\theta^{2}}\left[(\theta \operatorname{coth} \theta-\theta \operatorname{Cosech} \theta)\left(2-2 k-\gamma_{1}\right)\right]+j \omega C_{u} k$

here $\mathrm{C}_{\mathrm{u}}, \theta^{2}, \mathrm{k} \& \gamma$ are the constants so,

$\mathrm{Y}_{11} \Rightarrow \mathrm{Y}_{1} * \mathrm{Y}_{2} * \mathrm{Y}_{3}$

$Y_{11} \Rightarrow$ see Fig. 11(a)

Similarly, we have:

$\mathbf{Y}_{33}=\frac{j \omega C_{u}^{\prime}}{\theta^{2}}\left\{(\theta \operatorname{Coth} \theta-\theta \operatorname{Cosech} \theta)\left(2-2 k-\gamma_{3}\right)+j \omega C_{u}^{\prime} k\right\}$

where $\gamma_{3}=\mathbf{V}_{\text {sat }} / \mathbf{V}_{\text {sub }}$

$Y_{33} \Rightarrow$ see Fig. 11(b)

$$
\begin{aligned}
& Y_{31}=j \omega C_{u}^{\prime} \frac{\gamma_{3}}{2}-\frac{C_{u}^{\prime}}{C_{u}} Y_{11}, \gamma_{3}=\frac{V_{\text {sat }}}{V_{\text {sub }}}, Y_{11} \rightarrow \text { already calculated. } \\
& Y_{13}=-Y_{31} \\
& Y_{23}=\frac{i_{d}}{V_{\text {sub }}}=g_{o}\left\{(1-\mathrm{k}) \theta \operatorname{Cosech} \theta+\left(\gamma_{2}-1+\mathrm{k}\right) \theta \text { Coth } \theta\right\} \\
& \text { where } \gamma_{2}=\frac{V_{\text {sat }}}{V g_{D S}}
\end{aligned}
$$

$\mathrm{Y}_{21}=\frac{\mathrm{i}_{\mathrm{d}}}{\mathrm{V}_{\mathrm{g}}}=\mathrm{g}_{\mathrm{o}}\left\{(1-\mathrm{k}) \theta \operatorname{Cosech} \theta+\left(\gamma_{2}-1-\mathrm{k}\right) \theta \operatorname{Coth} \theta\right\}$

$Y_{12}=-Y_{21}$

$\theta \operatorname{Coth} \theta=\theta\left[\frac{1}{\theta}+1 / \frac{3}{\theta}+1 / \frac{5}{\theta}+1 / \frac{7}{\theta}\right]$

$$
=\frac{11 \theta^{4}+170 \theta^{2}+315}{\theta^{4}+65 \theta^{2}+315}
$$

$\left.\left.\theta \operatorname{Cosech} \theta=\theta\left[\frac{1}{\theta}+1 /\left(-\frac{6}{\theta}+1 /-\frac{10}{7 \theta}+1 / \frac{686}{11 \theta}\right)\right)\right)\right]$

$$
=\frac{77 \theta^{4}-2520 \theta^{2}+41160}{4340 \theta^{2}+41160}
$$




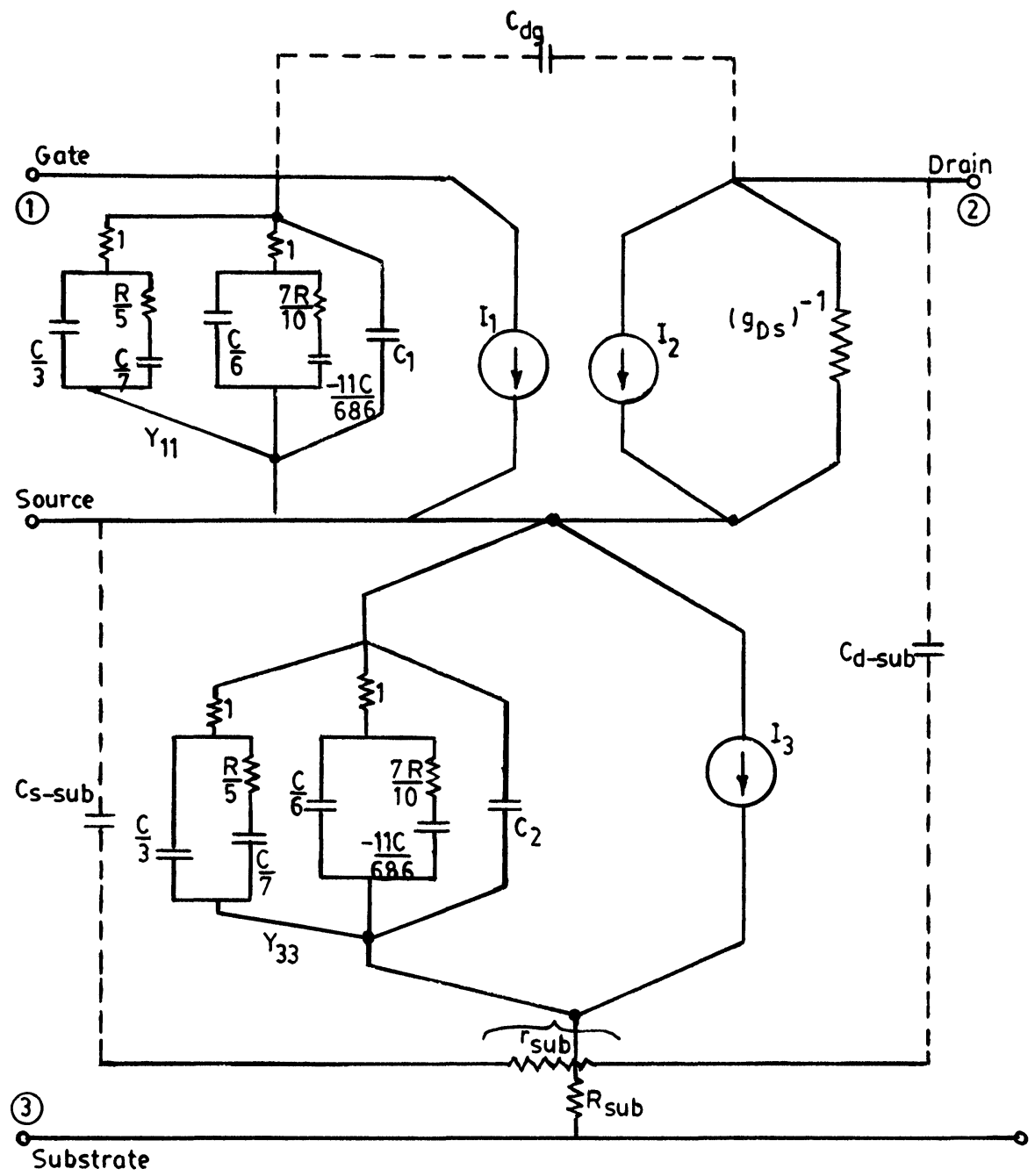

FIGURE 12 Accurate single-section model of MOSFET including substrate resistivity.

The current-source can be given as:

$$
\begin{aligned}
& I_{1}=Y_{13} \cdot V_{\text {sub }} \\
& I_{2}=Y_{21} \cdot V_{g}+Y_{23} \cdot V_{\text {sub }} \\
& I_{3}=Y_{31} \cdot V_{g}
\end{aligned}
$$

We have already calculated the values of $\mathrm{Y}_{12}, \mathrm{Y}_{13}, \mathrm{Y}_{11}, \mathrm{Y}_{21}, \mathrm{Y}_{22}, \mathrm{Y}_{23}, \mathrm{Y}_{31}, \mathrm{Y}_{32}$ \& $Y_{33}$ so by putting the values of constants the current sources can be determined. 


\section{CONCLUSION}

The usefulness of an RC double transmission line analog in the calculation of the 3-port admittance parameters of MOSTS, including substrate resistivity effects, has been established. It has been shown that the input capacitances and the gate and substrate transconductance, as measured at low frequencies, are the basic parameters that determine the essential Y-parameters of the device through certain mathematical relationships. In various modes of signal excitation and configuration of operation, it has been shown how to construct approximate HF equivalent circuits with a careful combination of intrinsic Y-parameters and the extrinsic RC properties of the device. Since the analysis relates the intrinsic network parameters to the basic device physical parameters, it should be possible to exploit them not only for the calculation of HF circuit performance of various types of MOSTS but also to improve the device performance through proper design and optimization of the structure itself.

Our proposed model of a 3-port, 4-terminal MOSFET, including substrate resistivity, is a very accurate model both in the frequency and time domains [Fig. 12]. This model is expected to affect considerable simplification and ease of handling of networks containing an interconnection of RC structures, lumped elements, and active elements. This work is superior to the earlier work by Lindholm and Gray ${ }^{2}$ in accuracy and simplicity.

\section{REFERENCES}

1. M.B. Das, "High-Frequency Network Properties of MOS Transistors Including the Substrate Resistivity Effects", IEEE Trans. Electron Devices, Vol. ED-16, no. 12, December 1969, pp. 10491069.

2. F.A. Lindholm and P.R. Gray, "Large Signal and Small Signal Models for arbitrarily doped four terminal field effect transistors", IEEE Trans. Electron Devices, Vol. ED-13, December 1966, pp. 819-829.

3. R.S.C. Cobbold and F.N. Trofimenkoff, "Four-terminal field-effect transistors", IEEE Trans. Electron Devices, Vol. ED-12, May 1965, pp. 246-247.

4. P.H. Hudson, F.A. Lindholm and D.J. Hamilton, "Transient performance of four-terminal fieldeffect transistors", IEEE Trans. Electron Devices, Vol. ED-12, July 1965, pp. 399-407.

5. S.C. Dutta Roy and Umesh Kumar, "A rational two-port model of the uniformly distributed RC structure”, IEEE Trans. Circuits and Systems, Vol. CAS-23, January 1976, pp. 56-58. 

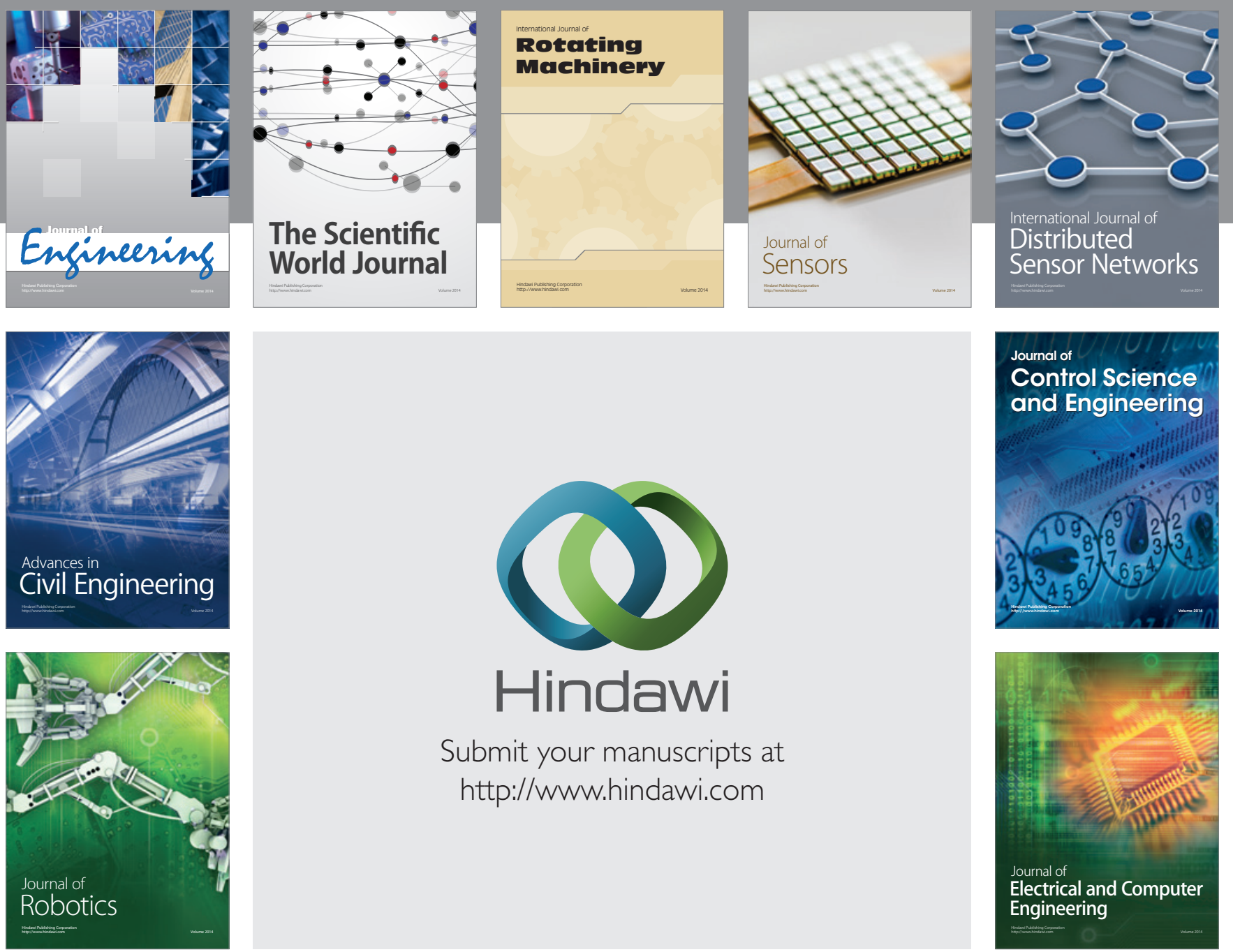

Submit your manuscripts at

http://www.hindawi.com
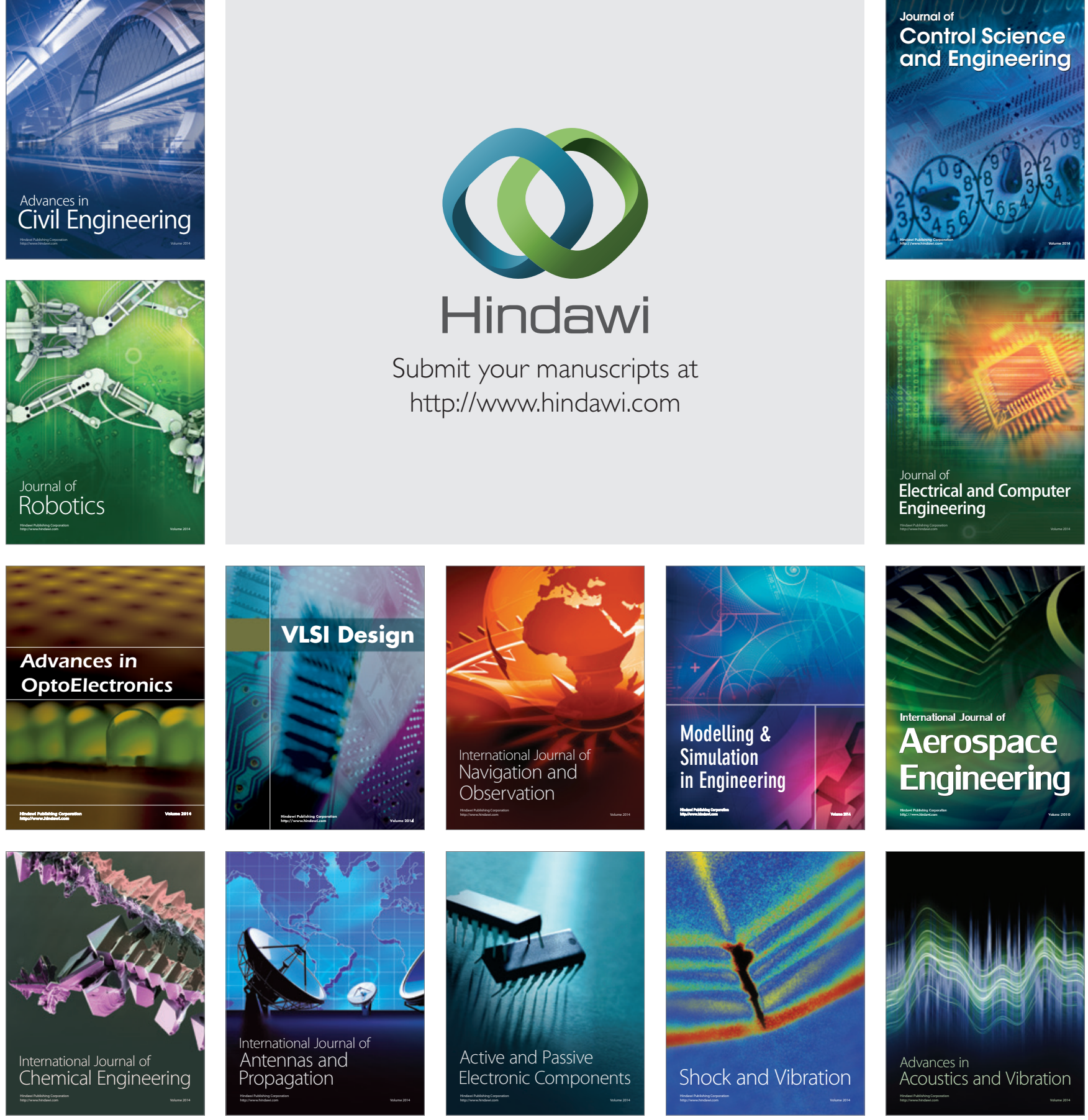